\title{
TV-ohjelman dialogi tuo luonnon kotiin
}

Kansainvälisissä ja useissa suomalaisissakin TV:n luonto-ohjelmissa on totuttu kuuntelemaan kaunista monologia, jossa selitetään, mitä tapahtuu. Katsoja on etäällä tapahtumista ja saa hyvän kokonaiskuvan. Tässä esiteltävässä turkulaisessa Luonto Plus -ohjelmassa katsoja on luonnossa kulkevien ja joskus myös konkreettisesti rämpivien Turun yliopiston eläinmuseon konservaattorin asiantuntija Ari Karhilahden (tässä AK) ja Turun Sanomien toimittajan Ann-Mari Rannikon (tässä $\mathrm{AR}$ ) mukana koko ajan ikään kuin itse löytämässä ja näkemässä. Alun perin ohjelma tuli Turun Sanomien paikallistelevisiosta Turku TV:stä. Se alkoi maaliskuussa 2002, ja sitä esitettiin säännöllisesti vuoteen 2012, jolloin paikallistelevisio lakkautettiin. Sen jälkeen ohjelmaa on voinut katsoa Turun Sanomien internetsivustoilta (Rönkä-Karhilahti-Rannikko 2018, 331; tstv.fi/video/). Uusia ohjelmia esitetään yleensä viikoittain; kesäaikaan on taukoja, ja joskus on myös jokin uusinta nähtävissä. Internetsivustoilta voi katsoa melko pitkältä ajalta vanhojakin ohjelmia.

TV:n luonto-ohjelmissa on edellä mainittujen monologien lisäksi dialogia, haastatteluja, keskusteluja, interaktiota yleisön kanssa ja kilpailuja. Niissä katsotaan yleisöön ja puhutaan yleisölle. Näin katsoja tuntee olevansa monenlaisen informaation kohteena. Luonto Plus -ohjelmassa taas ollaan rauhallisesti läsnä luonnossa varsinaissuomalaisessa maisemassa - välillä jopa arvailemassa sitä, missä oikeastaan ollaan.

Luonto Plus -ohjelmassa kieli ja keskustelu antavat maallikolle käsityksen luonnosta, joka ohjelmajakson ensimmäisessä kuvassa näyttäytyy vain pöheikkönä. Ohjelman edetessä vihreä pusikko tai ruskea hiekka ovatkin täynnä yksityiskohtia ja elämää. Kuulijalle vieraat asiat tulevat tutuiksi ja ymmärrettäviksi kaksikon ilmaisutavan ansiosta. Etsiminen ja löytäminen etenevät osin verkkaisestikin, ja katsojan on helppo samaistua toimittajaan ja hänen tapaansa hahmottaa asioita. 


\section{Katsoja konkreettisesti mukaan eläytymään}

Luonto Plus -ohjelman katsojat pääsevät mukaan luontoon eläytymään tunnelmaan ja tilanteeseen. Kun on kylmä tai jano tai jännittävä tilanne, AR saa välitetyksi kokemuksen muutamalla sanalla tai pikkulausahduksella: jos olis pukeutunut pilkkihaalareihin; nyt olis tarvinn_ollak kahvi mukan ${ }^{1}$. Kuiskaus antaa kuulijalle läsnäolon tunnun - ehkä minunkin on puhuttava hiljaa ja oltava varovainen TV:n ääressä, kun AR sanoo: jos olla iha hilja. Myös AR:n reaktiot $O i$ yäk! Hianoo! tekevät katsojan osalliseksi, kun hän pitää jotakin ällöttävänä ja esimerkiksi kauhistelee, säikähtää tai ihastelee.

Toimittajan into ja ihailu tarttuvat katsojaan, ja toisaalta realistinen pelkääminen, varovaisuus tai kauhistus sekä väsymys ja paleleminen tuovat ohjelmaan uskottavuutta. Lisäksi draamanomaisuus tekee sekä ohjelmasta että siinä esitellyistä asioista helposti lähestyttäviä; ei tarvitse olla varsinainen eränkävijä pystyäkseen liikkumaan luonnossa ja nauttimaan luonnosta.

Piikkiön Huttalan linnavuorella (7.2.2014) katsoja pääsee hartaaseen tunnelmaan ylhäältä ikiaikaiselta huipulta näkyvää maisemaa ihaillessaan. AK tuo paikalle ammoisten aikojen tiettömien taipaleitten ihmisen: [tässä] se on tajunnu et kauas om pitkä matka.

Ihminen lähestyy ohjelmassa koko ajan luontoa; kontaktipintoja on useita. Luontokappaleet nähdään kuitenkin varsin omaehtoisina olentoina: Ne [linnut] ei meilt mittän koskan kysy; ei voi käskyttä. Rual voi houkutella (AK). Ei ole kuitenkaan varmaa, että niitä onnistuisi näkemään.

Tunnelma ohjelmassa on luonteva ja kotoisa. Välillä mukaan on pujahtanut sisäpiirivitsejä: ...pajussa - pääasia, ettei juhapajussa. Lopputeksteistä katsoja huomaa, että ohjelman kuvaaja on nimeltään Juha Paju.

Jossakin määrin ote on myös kasvatuksellinen ja opetuksellinen. Katsojia valistetaan ja välillä myös puhutellaan. Välillä, kun keskustelu käy vapaana, AK saattaa sanoa: Älkää pitäkö tätä neuvona!

\section{Huoli luonnosta ja ihmisten toimista}

Toisinaan Luonto Plus -ohjelmaan tuodaan ekologinen ja yhteiskunnallinen näkökulma: pohditaan luonnon muuttumista ja ihmisen vaikutusta siihen. Välähdyksenomaisesti kuullaan esimerkiksi metsän lähellä oleva pikatie (28.2.2014).

AR: - - kauhea kolina ja paukek kuulu. Sivistys puske!

Linnavuorista (Rönkä ym. 2018, 152-155, 216-223, 296-300), joita on useilla Suomen paikkakunnilla, AK mainitsee ikään kuin sivumennen:

AK: Osa niist o jauhettu jo maantiäm pohjaks.

Erittäin selvästi luonnonsuojelunäkökulma tuli esiin 25.10.2013 esitetyssä lähetyksessä, jossa kaksikko oli tutkimassa Raision luontopolun alueella tehtyjä hakkuita. Myös ilmaisu sai tässä jaksossa luonnonsuojelullista sävyä.

1 Esimerkkien litteraatit kirjoittajan. 
Keskustelussa oli kuultavissa ihmettely, kun hallinnollisin toimin muka pyritään säilyttämään luontoa ja rakentamaan virkistysalueita, mutta silti tämä kaikki hyvä minimoidaan ja sitä häiritään ilmeisen tarkoituksellisesti. Tapahtunutta arvioidessaan AK käyttää ilmauksia suunnitelmallista ja tarkoituksenhakuista. Kun $\mathrm{AK}$ ja AR saapuvat paikalle, $\mathrm{AK}$ reagoi näkemäänsä seuraavasti:

AK: Tääll_o onnistuttu hienosti apteeraamaa ['hakkaamaan'] just liito-oraviem pesäpuut. - - Miks täsä, mis liito-oravat asuu, ni miks täsä täyty tehdä viis metrii leveest kahdeksa metrii ko muual on kolme metrii tää kaista. Levein kohta ladust ni levennetä edelle. Täss_o joku semmonen ko tietä mil saada liito-orava lähtemäm paikast.

Kaksikko puhuu naurettavasta operaatiosta ja atakista, jossa siis leveintä kohtaa ladusta levennetään, mutta jätetä resupuut pysty. AR murehtii: Kauhja suruliseks täst tulee. Ironiaa on kyseisessä jaksossa runsaasti. Liito-oravien kolopuiden kaatajien ja ladun leventäjien toimia arvioidessaan AR on matkivinaan näiden ajatuksia: Luonto tulee liia lähel, apua! (ks. uutinen "Liito-oravan kotimetsää kaatui Raisiossa", TS 24.10.2013). Erittäin oudolta asia vaikuttaa, kun kyseinen virkistysalue olis helppo suojella, sata hyvä laji pienel aluel (AK). AK katsoo laajaa peltoaukeata, johon ei ilmeisesti nyt juuri olla rakentamassa mitään, ja toteaa: Liito-orava joskus tulevaisuuden kaavaa varmaa jarruttaa.

Kyse on rikollisesta toiminnasta. AK sanookin: Täst täyty kannen nosta. AR pohtii oravien toimintaa: Tuski liito-orava täst ny mittäm pommi postis niill_ihmisil laitta. Hän myös miettii luonnonsuojeluun liittyvää lainsäädäntöä: Miks tämmösi lakei sit säädetä jollei niit kukka noudata? Kaksikko toteaa, että kun päätetään tehdä jotakin, perusteluja ei katsota tarpeellisiksi.

AR: $\quad$ sit ko haluu tehdä jonku jutska ni ei siin mittäm perustei tarvita se on nyt ihan höpömpöpö.

Pesäpuutuhot on katsastettu. AR sanoo lopputoteamuksessaan:

AR: Seuraavaks mennään kattoo sit tonne, mää en ol pitkää aikaa ollukkaa mittää juttuu tekemäs raastuvaoikeudes. Tästäpä sit seuraavaks tehää.

\section{Asiantuntijan ja toimittajan keskinäinen vuoropuhelu}

Karhilahden ja Rannikon keskustelussa on selvät roolit: rauhallinen asiantuntija ja hieman lapsekkaan innokkaaksi tekeytyvä toimittaja. Toimittaja on usein myös mukavuudenhaluinen ja säikkykin, asiantuntija taas rohkea ja eräkelpoinen.

AR pelkää ja välttelee AK:n paikalle tuomia hyönteisiä, isompia tai pienempiä. AR saattaa pyytää: Voidaanko toivoo, ettet päästä sitä lähemmäs! Usein toimittaja ei halua mennä aivan kaikkiin paikkoihin.

AK: Tää o sit vaa se verran kivikkoist.

AR: Käys sää sit siäl!

$--$

AR: Mää en tuls sinne alas. - - Sää uppoot nyt sinne. 
Osapuolet tulevat ajan kuluessa uusia jaksoja tehtäessä yhä läheisemmiksi toisilleen ja kiusoittelevatkin hyväntahtoisesti toisiaan. Keskustelu muuntuu välillä henkilökohtaisemmaksi:

AR: Tota, pystyks sää katsomaa ja puhumaa samaa aikaa, tota?

AK: $\quad$ mut ei tar... jos ei kävellä tarvii

Välillä viitataan aikaisempiin jaksoihin, välillä kyseisen jakson aiempaan keskusteluun: siinn_on ne sun kottaraises.

Metsäretkellä 21.2.2014 sytytellään itsetehtyä kahvinkeitintä, kun on tarkoitus keittää oikeaa nokipannukaffet. AR kiiruhtaa kahvinkeittoa. Sävyt ovat samanlaisia kuin perheenjäsenten kesken:

AK: No, älä vingus siin koko aika, sää olet nii malttamaton - aikune ihmine.

AR: Aikune ihminen, kuule!

AK: No, aikuisen kokone ihmine.

[Kahvinkeitto ei ole aivan nopeata. AK jatkaa tulen sytyttämistä.]

$--$

AR: $\quad$ Aikuiset o just noin tylsii

AK: $\quad$ - - mull olk ko seittämän tulitikku. - - Joku roti se pitä tyhmyreski olla sano ai pappa.

\section{Varsinaissuomalainen puhe}

Murteen käyttö tekee keskustelun luontevaksi. Kaksikon puhetyyli kuuluu varsinaissuomalaiseen maisemaan niin kuin paikallislehti mökkipaikkakunnalle. Puhujan oma kieli on esiteltävän alueen kieltä. Hän on juurtunut sinne ja on dialogissa tuttavien seurassa, ei vieraiden TV-katsojien. Viittaukset omaan pihaan ja sinne luonnosta tuotuihin kasveihin sekä itse poimittuihin sieniin ja niistä tehtyihin maukkaisiin ruokiin tuovat asiantuntijan lähelle katsojaa.

Pohdittavaksi kuitenkin jää, vieraannuttaako lounaissuomalainen puhetapa muualta Suomesta kotoisin olevia henkilöitä. Tosin runoilija Heli Laaksosen suosio saattaa antaa puheenparrelle miellyttävät assosiaatiot. Äänikirja Jänes pussis (Laaksonen 2003), jossa Laaksonen lukee runoja ensimmäisistä kokoelmistaan, on Suomen kaikkien aikojen suosituin äänikirja (Otava 2010). Lisäksi jopa vierasta murretta puhuvan asiantuntijan uskottavuus vahvistuu, kun hän kertoo, minkälaisia eläimiä tai eläinnäytteitä Turun yliopiston eläinmuseolle on eri vuosina tuotu ja minkälaisia ilmoituksia museo viikoittain saa maallikoilta esimerkiksi lintujen liikkeistä. Tätä ei siis kerro vain joku viestintäsihteeri tai tiedottaja vaan asiantuntija, joka itse tutustuu näytteisiin.

Toimittajan tausta on turkulainen, kun taas asiantuntijan isä ja tämän suku on Karjalasta, äiti on Turun Paattisilta. Paattinen luetaan kuuluvaksi Varsinais-Suomen ylämaan murteisiin (VarY, SMS). Sekä AR:n että AK:n puhetapa on helposti tunnistettavissa lounaissuomalaiseksi: Ensimmäisen persoonan persoonapronomini minä on mää; puhe on osin leveää eli diftongit avartuvat: vielä on viäl; loppuvokaaleita katoaa: välillä on välil; molemmilla konsonantit kahdentuvat lounaismurteiden mukaisesti: mäkke ylös, etteppäi, en voi muuta sanno. (Lyytikäinen 
et al. 2013, 17-20.) AK:lla konsonantti kahdentuu myös yksikön 3. persoonassa mm. se tekkee ja se näkkee, näkkyy, ruuam peräs ne mennee, vettä sattaa (ei turkulaista, esiintyy Paattisilla; ks. mts. 71). Lounaismurteiden pohjoisosassa sanotaan voi satta, mutta siäls sata, itäosassa voi satta ja siäls satta. (Mts. 20; Rapola 1966, 30-32; DMA.)

Konsonanttiyhtymä ts esiintyy asussa $t t$ jopa sanassa metsästää: en muista vuatta millo niit sai ruvet mettästämä. Sanoissa metsästää ja Ruotsi lounaismurteissa ts yleensä säilyy, kun taas sana metsä on tavallisesti asussa mettä ja ruotsalainen usein asussa ruattalaine(n). (Palomäki 1998, 146-150). Ohjelmassa esiintyy myös muoto kattottuna ja ilmaus kattosin, jossa on lisäksi turkulainen si-imperfekti (Koski ja Laukkanen 1989, 10; DMA). Lounaismurteelle tyypillisiä ovat ruotsalaiset lainat: entrata 'muuttaa, sortti 'laji', sorttimentti 'lajitelma', suntti 'salmi', trampattu'poljettu' jne. (Grönholm 1988).

Kuten yleensä kielenkäyttäjillä, toimittajan ja asiantuntijan puheessa esiintyy paljon vaihtelua. Verbeillä monikon 3. persoonassa he voivat samassa virkkeessä käyttää yksiköllistä ja monikollista asua: Nokikanat petti ja lähtivät poies. Samoin monikon perfektin sijaan saattaa olla puhutun kielen yksikkö: ne on sopinut. Väliin on kirjoitettuun kieleen kuuluva monikko: olivat yrittäneet tai ehkä onnistuneetki. Samassa jaksossa he käyttävät yleiskielen nopea-adjektiivista murteellista partitiivia nopiaa ja toisaalta nykypuhekielistä adverbiä nopeesti.

\section{Sanoista, termeistä, paikannimistä}

Murrepiirteiden ohella Luonto Plus -ohjelmassa on runsaasti nykypuhekielen (vrt. edellä) äänne- ja muotoilmiöitä, esim. ei lähekkää 'ei lähdekään' lähetään meneen (kuitenkin myös on jouduttu karsima), mää en tiiä sitä, ja myös slangisanoja, kuten skrode, joka tarkoittaa 'karkeaa, rotevaa', handu, tytsö. AK mainitsee kaatislinnut 'kaatopaikalla asuvat linnut' ja räksät 'räkättirastaat'. (Vrt. edellä ilmaukset jutska ja tehään.)

Usein kuulija saa myös nauttia hyvin värikkäästä kielestä - AR: pläjätti; (kielo) poksahta auki; AK: joku könyää ylös. Sanastoa, semantiikkaa ja historiaa yhdistetään hauskasti, kun keskustelussa puhutaan vanhan ajan ihmisen kulkuvälineestä vesillä: mainitaan paatti, ruuhi, haapio ja puunrunko.

Eri lajien nimityksissä saatetaan pohtia paikallista ilmausta: on sanottu Turus tämmöseks, tämmöseks; puhutan kukonkuusest. Usein kuitenkin käytetään virallisia nimiä ja termejä: limoniitti, paannejää ja raukki sekä luppo ja naava. Lupon ja naavan hienoista eroa ja tunnistamismahdollisuutta pohdittaessa syntyy oiva muistisääntö: naavan sisältä löytyy lanka tai naru, siis naru naavassa (alkusointu helpottaa muistamista).

AK välittää faktaa esimerkiksi kertoessaan kukan elinkierrosta ja alkueläimen aiheuttamasta kuputulehduksesta ja surviaissääskistä, tai hän selvittelee jonkin termin merkitystä (esim. juurellinen leviäminen) tai merkityksenmuutosta (esim. bongata). AK saattaa antaa hyvinkin tarkan lajinmäärityksen - usein hän vielä lisää esimerkiksi kahta lajia vertaillessaan: kumpaaki o montaa sorttii. AR taas puhuu yleisemmällä tasolla.

Paikannimiä ei aina mainita. Katsojalle jää sellainen kuva, että aivan tarkkaa paikkaa ei usein halutakaan kertoa. Olen ollut ymmärtävinäni, että näin halutaan estää ihmisten vaeltaminen kyseiseen paikkaan, jossa ehkä juuri lähetettävän jakson hetkellä on jokin arka lintu tai harvinainen kasvi. Vuonna 2015 ensimmäisen kerran ilmestynyt Mia Röngän, Ari Karhilahden ja Ann-Mari Rannikon Luonto Plus -ohjelmien kohteita esittelevä Turun seudun luontoretkiopas 
(Rönkä ym. 2018) tuo yleisön saavutettavissa olevat paikat vihdoin tavallaan kartalle.

Paikannimiin liittyvää pohdintaa on ollut runsaimmin Kullavuoren retkellä, jolloin kaksikko löysi alueen opasteista ja kartoista useita eri ilmiasuja kyseiselle paikannimelle: Kullavuori (Varsinais-Suomen liitto), Kullaanvuori (Raision retkeilykartan sivusto), Kullanvuori (Maanmittauslaitoksen Karttapaikka), Kullaan Wuori. Paikan päällä on kallioon hakattuna Kulla Wuori 1935. Lisäksi AK muistaa nuoruudestaan nimityksen Kuuanvuori. Kun näitä nimiä on yhdessä pohdittu, AK kysyy: Ollanks me nyt sit ainaki neljäl erinimisel mäel sama aikaan ku ollan täsä? AK oli kysellyt nimen alkuperää samana päivänä suomen kielen professorilta Kaisa Häkkiseltä. Nimi ei liity kultaan eikä tyttökultiin vaan on alun perin germaanisperäinen laina, joka viittaa mäkeen, siis korkeampaan paikkaan; nimi on vielä myöhemmin uudelleen lainattu ruotsista merkityksessä 'huippu'. (Ks. Rönkä ym. 2018, 200-205 sekä paikkahakemisto s. 351.)

Toki muissakin jaksoissa nimiä on mainittu: Ukko-Pekan sulassa uivat sorsat talvellakin, Hauniste alttal o lammikei. Vuosien 2013-2014 jaksoissa olen havainnut huomattavan paljon paikannimiä: Luolalanjärvi, Piikkiön Huttalan linnavuori, Raision Somersoja, Rauvolanlahti. (Rönkä ym. 2018 ja paikkahakemisto s. 351-353.)

\section{Luonnon ja eläinten inhimillistäminen}

Vuoden 2008 Sananjalassa (Siitonen 2008) olen kirjoittanut Luonto Plus -ohjelmasta lähinnä luonnon ja eläinten inhimillistämisestä pääasiassa hän-pronominin käytön näkökulmasta. Pohdin myös kognitiivisten verbien käyttöä ja henkilötekijäiseltä vaikuttavan passiivin käyttöä.

Olen todennut artikkelissani, että toimittaja (AR) käyttää puheessaan hyvin paljon hänpronominia eläimistä, kun taas asiantuntija (AK) käyttää yleensä se-pronominia. Olin seurannut koko talvikauden 2007-2008 Turku-TV:n Luonto Plus -jaksoja. Vasta 14.3.2008 tavoitin asiantuntija AK:lta ensimmäisen hän-pronominin eläimestä. AK esitteli jaksossa kauriin asuinpaikkaa sekä elämäntapoja ja käytti koko ajan se-pronominia. Lopuksi hän kuitenkin sanoo jälkiä osoittaen: Täs hän [kauris] on nyt sit kävelly." (Siitonen 2008, 98.)

Sävypronomini-artikkelini kirjoittamisen jälkeen olen kirjannut vielä muutamia uusia inhimillistämisteemaan liittyviä esimerkkejä.

Sekä AK että AR käyttävät usein passiivia puhuessaan eläinten tekemisistä:

AK: Täss_o sit vissi väärälaist heinä et ei ol maistunu ko ei ol oike alotettukka AR: - - ehkä järjestelmällisesti ni edetään niinku vasemalt... vasemalt oikialt meist kattottuna et

AK: jos ne o sopinu et tähäm peltoo mennä myöhemi vast tai se o varattu kanadahanhil

Suokukasta puhutaan seuraavassa sekä passiivissa että henkilöön viittaavaa pronominia käyttäen:

AR: Ollaa noi näkyvä värine.

AK: [Suolla kasvavista kukista] ei os syyskukkija kukka [= kukaan].

Sanavalinta - niin substantiivien kuin verbienkin osalta - viittaa usein ihmisten toimintaan: sanaa partiokaveri käytetään viittaamassa toiseen saman lajin lintuun, ja edellä oleva AK:n ilmaisu jos ne o sopinu [eläimet keskenään] heijastaa vuorovaikutusta ja suunnitelmallisuutta 
eläinten toiminnassa. Seuraavassakin olevat verbit sopisivat hyvin kuvaamaan ihmisen toimintaa:

AK: Varikset ja naakat hyärää; Haukka häiväsee.

Sammakon kutemista seuratessa käytetään useita edellä esittämiäni inhimillistämiskeinoja: on niin ko formulatalli käynnistämäs vehkeitä [sammakot kutemassa]; puhutaan sammakon toiminnasta ja ikään kuin sammakon omista ajatuksista: nyt tää homma hoidetaan [siis sammakot kutemisensa]. AR yöllä kylmässä olleista sammakoista: aika totisen näköst porukka.

Asiantuntija pohtii lintujen elämää Suomessa. Muuttolinnuille olisi hyvä antaa tietoa Suomen olosuhteista - vaikkapa luettavassa muodossa: Pitäisi laittaa prošyyria Afrikkaan...

\section{Keskustelu innostaa lähtemään itsekin luontoon}

Kaksikon dialogi muovaa maisemat ja polut, avaa salaisuuksia ja ennakoi yllätyksiä. Keskustelu kuljettaa pitkospuiden luo. Se johdattelee katsojaa omiin pohdintoihin luonnosta ja omiin tutustumisretkiin. Tuttu puhetapa, tutut äänet ja ilmeet, yhteinen kotiseutu ja ainakin asiantuntijan mielestä melkoisen turvalliset tienoot innostavat. Kyseessä on tiettömiäkin taipaleita, mutta nekään eivät ole kaukana kaupungeista. Luolat kätkeytyvät lähimetsiin - usein kaupunkibussilla tavoitettaviin - ja uudet maisemat avautuvat yllättäen tutuissa ympäristöissä, ja näkymä on laaja ja kaunis.

Tarina ja puhe tekevät paikoista kiinnostavia ja samalla jännittäviä. Usein asiantuntijan ja toimittajan huumori saa hymyn katsojan/kuulijan huulille ja panee odottamaan seuraavia seikkailuja.

Katsaus on muokattu versio Turun Sanomien digilehdessä 2.5.2015 ilmestyneestä jutusta. Kiitän Mia Rönkää käsikirjoitustani koskevista arvokkaista kommenteista.

Kirsti SitTonen

Suomen kieli ja suomalais-ugrilainen kielentutkimus 20014 Turun yliopisto

\section{Lähteet}

DMA = Digitaalinen Muoto-opin arkisto. Käytettävissä kielipankissa https://www. kielipankki.fi/. GröNHOLM, MAIJA 1988: Ruotsalaiset lainasanat Turun murteessa. Väitöskirja. Åbo akademi, Turku. Koski, Mauno - LaukKanen, Esa (toim.) 1989: Kummottos : Turun murteen sanoja ja sanontoja. Turkuseura, Turku.

LAAKsonen, Heli 2003: Jänes pussiss. Korvallissi runoi. CD-äänilevy + tekstiliite. Sammakko, Turku.

Lyytikäinen, Erkki - Rekunen, Jorma -Yli-PaAvola, JaAkko (toim.) 2013: Suomen murrekirja. Gaudeamus, Helsinki.

Otava $2010=$ ks. https://otava.fi/kirjat $/ 9511206974$

PalomäKI, Ulla 1998: Dentaalisen affrikaatan perilliset Suomen murteissa. Kielikontakteihin perustuva selitysmalli. Turun yliopiston suomalaisen ja yleisen kielitieteen laitoksen julkaisuja 59. Turun yliopisto.

RAPOLA, MARTTI 1966: Suomen kielen äännehistorian luennot. SKST 283. SKS, Helsinki. 
Rönkë, Mia - Karhilahti, ARI - Rannikko Ann-Mari 2018: Turun seudun luontoretkiopas. Kolmas, uudistettu painos. Sammakko, Turku.

SiItONEn, KiRSTI 2008: Sävypronomini hän. Sananjalka 50, 87-109.

SKS = Suomalaisen Kirjallisuuden Seura.

SKST $=$ Suomalaisen Kirjallisuuden Seuran Toimituksia. Helsinki.

SMS = Suomen murteiden sanakirja 1985. Kotimaisten kielten tutkimuskeskuksen julkaisuja 36. Kotimaisten kielten tutkimuskeskus, Helsinki.

TS $=$ Turun Sanomat .

tstv.fi/video: Luonto Plus -hakusanalla uudet ja aikaisempien vuosien videot. 